\title{
Asian Tigers, Pacific Panthers
}

\section{Even Asia-Pacific's smaller players - notably Singapore, Taiwan and New Zealand - work to improve their scientific and technical capabilities, while several tiny nations in the region are beginning to shine.}

\section{SINGAPORE}

ARTICLE COUNT (AC): 873

FRACTIONAL COUNT (FC): 521.40

WEIGHTED FRACTIONAL COUNT (WFC): 520.60

Singapore's reputation for science and technology has long belied its small size. The island nation has a population of just 5.5 million people, but boasts one of the world's highest numbers of scientists and engineering researchers per capita. As the country celebrates its 50th birthday this year, Singapore can proudly point to its global standing in the fields of electronics, petrochemicals and, of late, pharmaceuticals.

More than 30 of the top global drug companies have a presence in Singapore, collectively spending approximately US $\$ 500$ million per year on research and development. Amgen, the world's largest biotechnology company, is constructing its first Asian manufacturing facility in Singapore while Novartis, the Swiss pharma giant, is building a new biological drugs production plant that should be operational by 2017. Novartis already has a few production plants in Singapore, as well as the company's Asia-Pacific headquarters, the Novartis Institute for Tropical Diseases.

Singapore has achieved its scientific prominence, in part, by forging international partnerships to bolster its research credentials. In
May 2014, for example, the National Research Foundation of Singapore signed an agreement with the French National Research Agency to jointly fund three-year basic research projects in materials science and nanotechnology. Scientists involved in each collaborative Franco-Singaporean project will receive up to US $\$ 590,000$, with equal funds provided by each country. In July 2014, Singapore also joined the Human Frontier Science Program, which funds international collaborations in the life sciences.

\section{"SINGAPORE HAS THIS BIODIVERSITY THAT HASN'T BEEN MAPPED"}

Individual research institutions in Singapore have also forged alliances with top-tier universities in Europe, the United States and elsewhere. This spirit of collaboration is spreading into industry.

Last year, for example, the governmentbacked Agency for Science, Technology and Research $\left(A^{\star}\right.$ STAR $)$ and the Swiss food giant Nestlé agreed to work together to study how natural processes, such as fermentation, can transform raw ingredients into foods that are more digestible or have extended shelflives. Meanwhile, the National University of
Singapore (NUS) partnered with Californiabased Agilent Technologies to develop the first database of lipid, or fat, levels among healthy people of different racial and ethnic backgrounds. In 2014, A ${ }^{\star}$ STAR also entered a fiveyear research arrangement with GE Healthcare to build new medical scanning technologies that improve on computed tomography and magnetic resonance imaging.

Many of Singapore's scientists and engineers are native to the country, but it continues to attract top researchers from around the world. Academics are often drawn to Singapore's international atmosphere and the funding opportunities for a range of long-term support options. One recent recruit was James Best, a leader in the fields of diabetes and kidney research. Best left his post at the University of Melbourne in Australia last year to serve as dean of the Lee Kong Chian School of Medicine at Nanyang Technological University (NTU) in Singapore. Best praises Singapore's "optimistic and positive culture," which he says places exceptional emphasis on education, as well as the country's high level of research investment.

To foster talent, focused research centres are being established across the country. In October 2014, for instance, NTU opened the Photonics Institute to explore research involving light technologies, such as those found in fibreoptic cables, lasers and consumer electronics.

\section{SINGAPORE ANALYSIS}

Top ten institutions

Only Singapore's top three institutions in the Nature Index (NI) make a significant contribution to publishing in science and technology, based on their WFCs.

\begin{tabular}{llrr} 
RANK & INSTITUTION & WFC 2014 & AC2014 \\
\hline 1 & Nanyang Technological University (NTU) & 199.86 & 371.00 \\
2 & National University of Singapore (NUS) & 190.30 & 465.00 \\
3 & Agency for Science, Technology \& Research (A*STAR) & 100.33 & 284.00 \\
4 & Singapore University of Technology \& Design (SUTD) & 8.50 & 24.00 \\
5 & National Research Foundation (NRF) & 4.57 & 35.00 \\
6 & National University Health System (NUHS) & 1.40 & 18.00 \\
7 & National Cancer Centre Singapore & 1.11 & 7.00 \\
8 & National Neuroscience Institute (NNI) & 0.85 & 4.00 \\
9 & Defence Science and Technology Agency (DSTA) & 0.58 & 3.00 \\
10 & Singapore General Hospital & 0.55 & 7.00
\end{tabular}

Top five collaborators

About $40 \%$ of Singapore's NI articles include international collaborators, and China runs a close second to the United States.

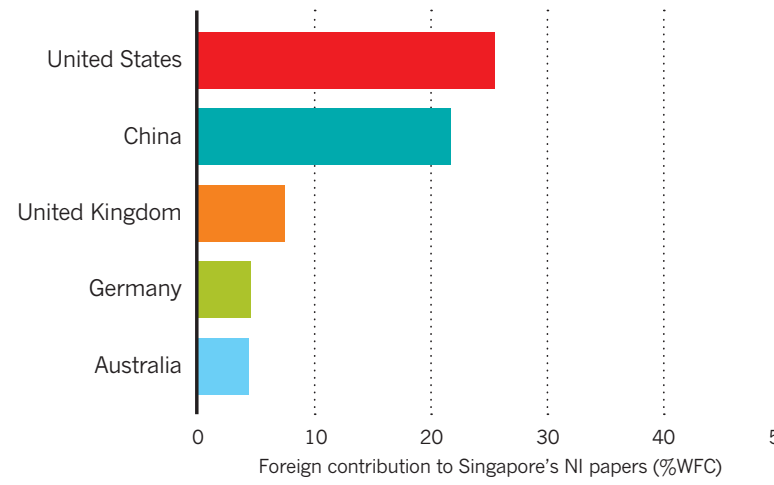




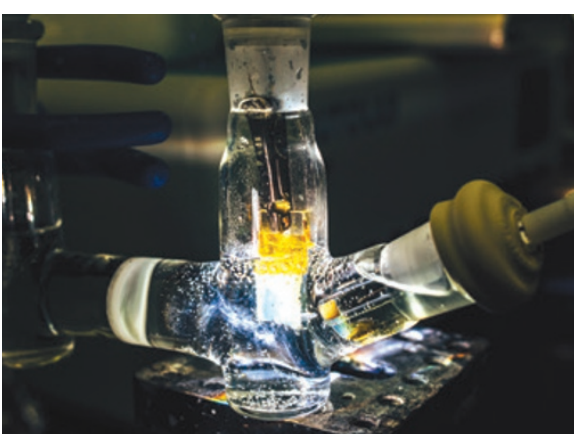

Researchers at NTU Singapore study light technologies, such as this artificial leaf.

A month earlier, NTU had joined forces with A ${ }^{\star}$ STAR and the National Healthcare Group to launch the Rehabilitation Research Institute of Singapore, which aims to make advances in areas such as stroke recovery, clinical robotics and biomechanics.

Meanwhile, as part of an effort to understand health issues unique to Asian populations, the NUS Yong Loo Lin School of Medicine recently opened the doors of its new Centre for Translational Medicine. The centre will focus on two areas of research that particularly affect Singapore and the region, including diseases such as liver cancer that are more common in Asian populations. It will also investigate why Asian people respond to drug therapies differently than people in the West. In line with the "translational" part of the centre's remit, basic life scientists work "right next to clinicians in the same building," says Barry Halliwell, deputy president for research and technology at NUS.

In February 2015, the NUS Lee Kong Chian Natural History Museum also unveiled its Animal and Plants of Singapore project, which tracks research and observations about the country's flora and fauna, especially in the face of climate change.

"Until recently most of Singapore's research into life sciences has been in the biomedical arena," Halliwell says. "But we're now more conscious of the fact that Singapore has all this biodiversity around us that really hasn't been mapped."

In addition, all the buildings, infrastructure, land and environment of Singapore are being mapped through the country's Smart Nation Initiative, a major new government investment in information technology.

One of the first projects of this programme involves building a sophisticated threedimensional model of Singapore for researchers to run large-scale simulations of cell phone-coverage patterns, evacuation measures and other engineering issues that instruct the work of city planners.

\section{TAIWAN}

ARTICLE COUNT (AC): 887

FRACTIONAL COUNT (FC): 520.18

WEIGHTED FRACTIONAL COUNT (WFC): 481.36

Among the Asian Tigers - the economically emergent nations of the Pacific Rim - Taiwan has been a strong contender in engineering, computer science, materials and condensed matter physics. Almost $90 \%$ of its publications in the 2014 Nature Index were in chemistry or physical sciences. That bedrock will be strengthened in the coming year with the opening of the Taiwan Photon Source, a physics research facility that will accelerate electrons to energies exceeding three gigaelectronvolts, making it one of the world's brightest $\mathrm{X}$-ray sources.

The new research centre complements the older Taiwan Light Source, which opened more than 20 years ago at the National Synchrotron Radiation Research Center (NSRRC) in Hsinchu City with only half the energy capacity. "The Taiwan Photon Source will provide one of the best medium energy storage rings in the world, which will be very useful for imaging, diffraction and spectroscopy research," says Shih-Lin Chang, a physicist who directed the Hsinchu facility from 2010 to 2014.
Taiwan is also scaling up its efforts in climate sciences with the country's first petabyte-scale database for assessing conditions related to atmosphere, hydrology, ocean currents and tectonics. ( 1 petabyte is $10^{15}$ bytes, or 1,000 gigabytes.) The new Earth Science Observation Knowledgebase (ESOK) holds more than 10 million satellite images, shock-wave records and other measurements from an array of national academic sources. With the ability to access 18,000 data points per second, ESOK will serve scientists as they model the impact of climate change and natural disasters.

Taiwan's National Space Organisation last year also unveiled a new satellite component that should help the country create its own space technology. In the past, Taiwanese satellites have relied on foreign equipment, which is tightly regulated by export controls. The new component helps satellites to receive signals from global positioning systems and to transmit photos with improved resolution. Officials expect the component will be installed on the Formosa-7 satellite, which is set to be launched in 2018.

In the biological sciences, Taiwan is creating major new research facilities. Last year, the government built a new marine biology and ecology research centre on Dongsha Island - a tiny coral atoll 450 kilometres southwest of the main island of Taiwan. With a focus on environmental protection and sustainable development, the new centre boasts wave- and water-quality monitoring devices, marine biology laboratories and research vessels.

Meanwhile, Academia Sinica, the country's national academy with more than 900 researchers, is building a National Biotechnology Research Park, set to open in Taipei's Nankang District in 2016. The park will expand the country's capacity for translational medicine - the conversion of basic scientific discoveries into health benefits - as well as provide a home for startup drug companies.

Not all new infrastructure projects have gone according to plan. In recent years, Taiwan

\section{TAIWAN ANALYSIS}

Top ten institutions

NTU and Academia Sinica account for nearly $50 \%$ of the NI articles published by the top ten institutions.

\begin{tabular}{llrr} 
RANK & INSTITUTION & WFC 2014 & AC 2014 \\
\hline 1 & National Taiwan University (NTU) & 106.54 & 294.00 \\
2 & Academia Sinica & 81.86 & 482.00 \\
3 & National Tsing Hua University (NTHU) & 65.28 & 171.00 \\
4 & National Chiao Tung University (NCTU) & 46.60 & 99.00 \\
5 & National Cheng Kung University (NCKU) & 19.28 & 60.00 \\
6 & National Taiwan Normal University & 17.80 & 45.00 \\
7 & National Central University (NCU) & 15.60 & 112.00 \\
8 & National Sun Yat-Sen University (NSYSU) & 12.78 & 29.00 \\
9 & National Chung Hsing University (NCHU) & 10.49 & 21.00 \\
10 & National Synchrotron Radiation Research Center (NSRRC) & 10.22 & 35.00
\end{tabular}

Top five collaborators

About half of Taiwan's NI publications include international collaborators, and about $20 \%$ of them come from China and Japan.

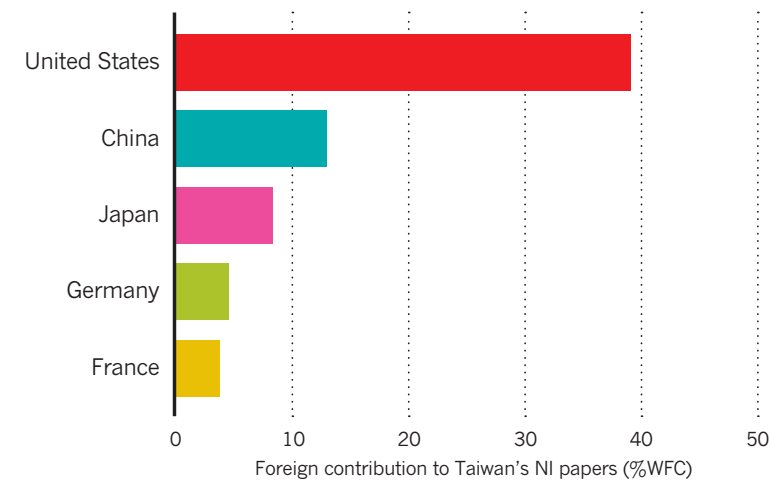




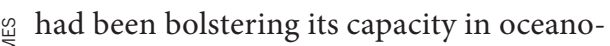
graphic research. But tragedy struck in October 2014 when the country's RV Ocean Researcher $V$-a 73-metre, 2,700-tonne research vessel - sank in rough seas in the Penghu Passage between Taiwan and China. The shipwreck, less than two years after the boat's maiden voyage, killed two scientists and scuppered more than a dozen research projects. Liang-Saw Wen, deputy director of the Taiwan Ocean Research Institute in Kaohsiung, admits to "facing very severe setbacks."

Taiwan's government pledged to restore and strengthen its oceanic research capacity with the construction of a new large vessel and the purchase of other smaller ones. "Hopefully, we will be back in business in full stride soon," says Wen.

\section{NEW ZEALAND}

\section{ARTICLE COUNT (AC): 275 \\ FRACTIONAL COUNT (FC): 102.96 \\ WEIGHTED FRACTIONAL COUNT (WFC): 95.69}

New Zealand is well known for its sheep and spectacular scenery, and those national assets undoubtedly influence the country's research agenda. Case in point: researchers at the government-funded New Zealand Agricultural Greenhouse Gas Research Centre in Palmerston North are leading global efforts to develop a vaccine that can reduce methane emissions from livestock. But the country is hoping to add high-value research in health, housing and new technologies to its national output. For now, about a third of its publications are in life sciences, according to the 2014 Nature Index.

Last year, the government launched its National Science Challenges initiative, which will contribute more than US $\$ 23$ million per year to 11 scientific areas of particular national relevance. These include studies of resilience to natural disasters, nutritional interventions, biosecurity and explorations of Antarctica's

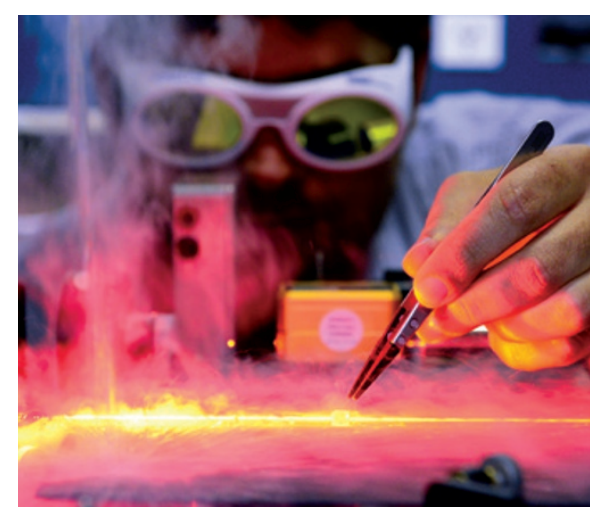

At New Zealand's Dodd-Walls Centre, many scientists study photonics, such as the rare earth ion-doped crystals being used here to detect ultrasound.

impact on New Zealand's climate. Notably, the National Science Challenges will provide the money to interdisciplinary, multi-institutional teams for ten years - much longer than the typical three- to five-year grant cycle.

The National Science Challenges programme is in addition to new investments in the country's Centres of Research Excellence (CoRE), which, since 2002, have built New Zealand's research capacity in targeted scientific areas. The newest CoREs, funded from 2015 to 2020 , focus on medical technologies, human disease, advanced materials, photonics, complex networks and brain research.

\section{"WE AIM TO MELD THIS STRENGTH INTO A COHERENT RENOWNED WHOLE"}

Each centre serves as a collaborative hub for research and training. "We have numerous world-recognized individuals," says David Hutchinson, director of the Dodd-Walls Centre for Photonic and Quantum Technologies, a new
CoRE at the University of Otago in Dunedin. "The CoRE aims to take this strength and meld it into a coherent, world renowned whole."

To turn basic scientific discoveries into commercial products, the New Zealand government launched a programme in 2013 to help build new start-up companies from emergent technologies. The Callaghan Innovation (named after physicist Sir Paul Callaghan, who died in 2012), has forged partnership arrangements with more than 20 research organizations across New Zealand. In 2014, the programme created a number of incubators to nurture fledgling firms. "We support New Zealand businesses developing or commercializing high value products and services," says Mary Quin, Callaghan Innovation's chief executive. "This includes providing access to the specialist research, engineering and commercial expertise, and research funding they need to gain a technical edge on the competition."

The country's largest newspaper, the New Zealand Herald, named Quin, a materials scientist, as the New Zealander of the Year for 2014. But perhaps no scientist is as well known to the New Zealand public as the country's Chief Science Adviser, Peter Gluckman. In his five years in the post, Gluckman, a paediatrician who studied developmental endocrinology and neuroscience at the University of Auckland before entering government in 2009, has been a key voice informing debate around issues as varied as childhood obesity, fluoride treatment of water, and climate change.

In March 2014, Gluckman authored a policy document in Nature outlining ten principles for building public trust and government influence. Months later, he hosted the first global conference on science advice to governments. The meeting - held in Auckland in August brought together about 200 participants from more than 40 countries that shared practices and perspectives in the provision of advice in the scientific arena. Gluckman is leading efforts to build a more formal network of science advice practitioners.

\section{NEW ZEALAND ANALYSIS}

Top ten institutions

Compared to the leaders in the Asia-Pacific, New Zealand scientists publish very few NI papers.

\begin{tabular}{llrr} 
RANK & INSTITUTION & WFC 2014 & AC 2014 \\
\hline 1 & University of Otago & 27.79 & 79.00 \\
2 & The University of Auckland & 20.97 & 132.00 \\
3 & Victoria University of Wellington & 12.47 & 62.00 \\
4 & GNS Science & 7.93 & 30.00 \\
5 & University of Canterbury (UC) & 7.47 & 101.00 \\
6 & Massey University & 5.16 & 39.00 \\
7 & National Institute of Water \& Atmospheric Research (NIWA) & 4.25 & 28.00 \\
8 & University of Waikato & 2.24 & 13.00 \\
9 & AgResearch & 1.43 & 5.00 \\
10 & Lincoln University & 1.23 & 3.00
\end{tabular}

Top five collaborators

About $65 \%$ of New Zealand's $\mathrm{NI}$ articles include collaborators from other countries, and the only top source in the region is neighbouring Australia.

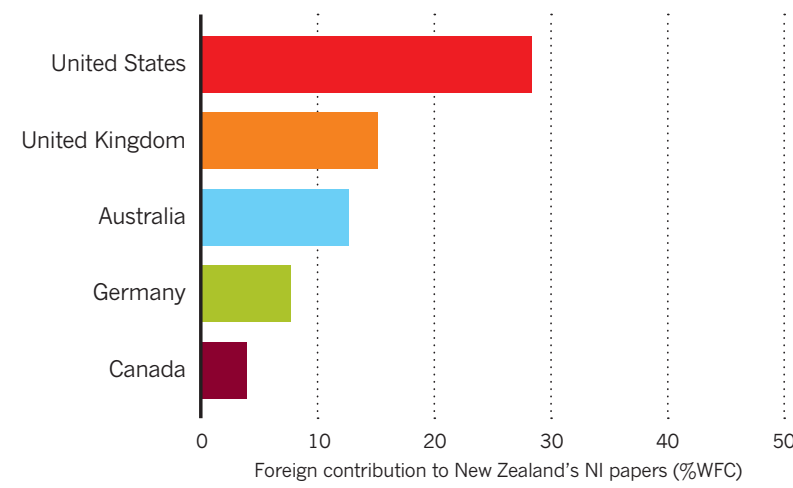




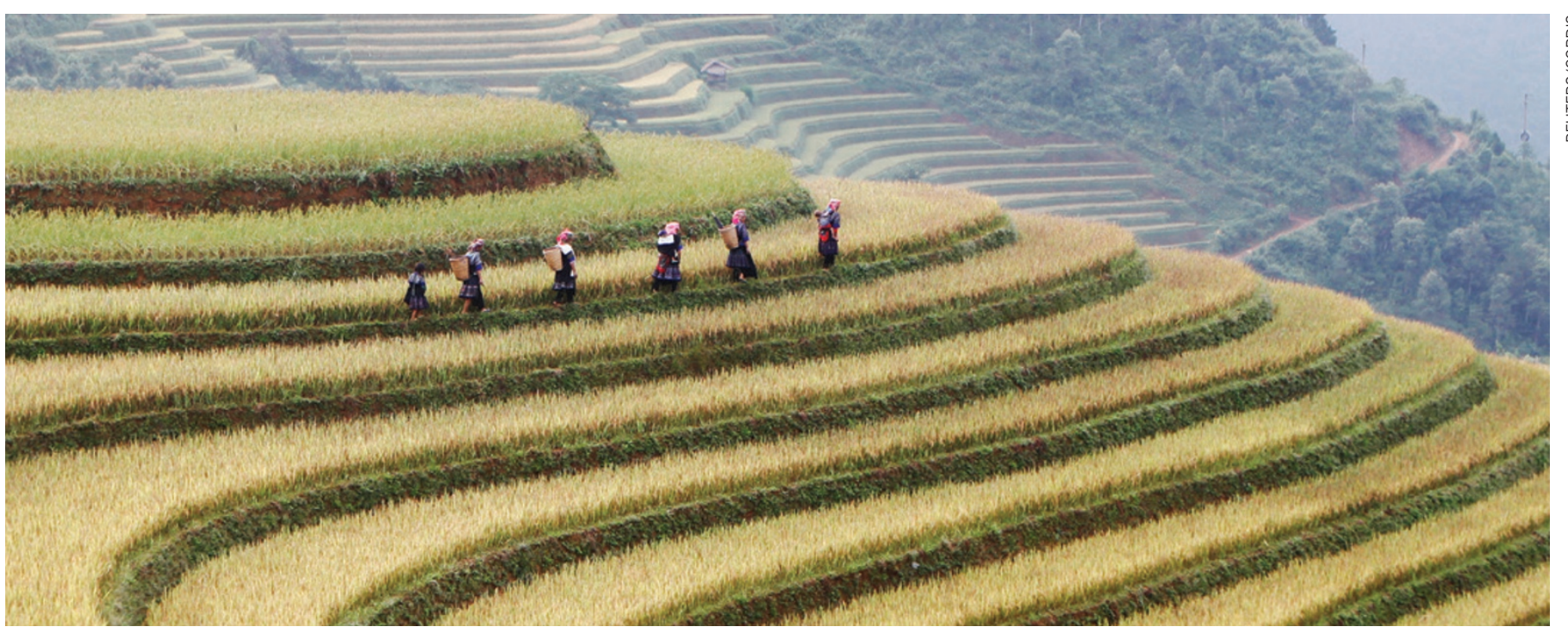

Farmers expect better yields from new forms of rice, such as those developed at Vietnam's Agricultural Genetics Institute.

\section{OTHER COUNTRIES}

Vietnam had much to be proud of in 2014. The country's Agricultural Genetics Institute received international accolades for developing hardier varieties of rice and soybeans; researchers at the Vietnam Academy of Science and Technology created steel from red mud; and Vietnam became the second Asian country to develop, test and produce an anti-diarrhoeal vaccine for children. Also in 2014, Vietnam celebrated its first Science and Technology Day. This new national holiday will be held annually on 18 May to honour scientific achievements in the country and to raise awareness of the social, physical and natural sciences.

Bangladesh is making huge strides in research and technology. Through its Vision 2021 development programme, the country is starting to focus on telecommunications, transportation and aquatic research. But the most significant achievements continue to be made in the health sciences - in particular by researchers at the International Centre for Diarrhoeal Disease Research, Bangladesh (ICDDR,B) in Dhaka. Last year, for example, scientists from the 50 -year-old ICDDR,B published two papers in Nature describing how gut microbes affect healthy growth in children and recovery from cholera in adults. "Our ultimate goal is to improve the health conditions of the children who are suffering from infectious diseases and malnutrition," says Rashidul Haque, head of the parasitology laboratory at ICDDR,B.

Many of the countries in the Asia-Pacific region often serve as test sites for clinical trials involving diseases endemic there. Last year, Sanofi Pasteur, the French vaccine giant, published the first ever phase- 3 clinical trials for a vaccine candidate for dengue fever, a mosquito-borne illness with no proven vaccines or antiviral drugs. That trial took place in five countries: Indonesia, Malaysia, Philippines,
Thailand and Vietnam. Maria Rosario Capeding, who led the study, from the Research Institute for Tropical Medicine in the Philippines, says these sites were chosen for their "exemplary capabilities and the efficiency of the clinical trial teams in this region." In 2015, the first in-human clinical trial of an experimental leprosy vaccine will also be conducted in the Philippines.

\section{"IT WILL FIND SOUND SOLUTIONS ACCEPTABLE TO LOCAL CULTURE"}

Many current and former US territories in the South Pacific are beefing up their biomedical research capacity. Last year, the Republic of Palau became the latest nation to open a training laboratory under the Pacific Short-Term Education Program for Underrepresented Persons (STEP-UP). The hope is that STEPUP will "increase the pipeline of underrepresented or disadvantaged individuals engaging in health and biomedical research," says programme director, George Hui, a malaria vaccine researcher at the University of Hawaii. "It will find solutions that would be scientifically sound and acceptable to the local culture and community practices."

Since 2010, the programme has helped establish similar facilities at the American Samoa Community College, the Northern Marianas College, the College of the Marshall Islands and the College of Micronesia.

Also in the South Pacific, the tiny island chain of Kiribati is making a big contribution to conservation research. In July 2014, President Anote Tong pledged to ban all commercial fishing in the country's Phoenix Islands Protected Area. "Its closure will make a major contribution to the conservation and rejuvenation of fish stocks and to global food security," Tong told delegates of the 2014 Our Ocean conference. The 40 million hectare reserve will remain open to scientists hoping to study tuna, sharks and other tropical fish species.

Outside conservation and ecology, however, few of the island nations that dot Oceania have a significant influence on the global science enterprise. Individually, each country is too small. But collectively, they could have a much bigger impact and a new cooperative agreement is helping foster the necessary international scientific teamwork. At the Pacific Islands Leaders Forum held in Palau in July 2014, more than a dozen countries agreed on a new Framework for Pacific Regionalism, committing to advance integration on a range of issues, including intellectual property rights and scientific projects. Among other goals, the framework promises to spur joint agricultural research on crops endemic to the Pacific rim.

In Southeast Asia, ten countries are also joining forces in 2015 to formally launch the integrated ASEAN Economic Community. The new single market - which encompasses Indonesia, Malaysia, the Philippines, Singapore, Brunei, Vietnam, Laos, Myanmar, Thailand and Cambodia - will advance scientific cooperation in the fields of food science, biotechnology, meteorology, microelectronics and space technology, among other disciplines. Scientists, engineers and doctors will be able to move more freely between countries. Laboratory testing and customs procedures will be harmonized. An Asian power grid will be built that draws on biofuels and other alternative energy sources.

Research innovation is becoming an increasingly global phenomenon. And, as it does, traditional national borders could become less significant - good news for the smaller players in the Asia-Pacific region, and positive for scientific enterprise as a whole. 